\title{
The Controversial Economics of the Brandt Report*
}

\section{Graham Bird}

The purpose of this article is not to examine in detail the range of specific proposals that are advocated in the Brandt Report but rather to extricate from it the underlying economic principles upon which these are based, to examine the validity of these principles and to draw attention to the availability of alternative analyses and policy prescriptions.

On the basis of any criterion, the world economy has performed poorly in the period since the first substantial increase in oil prices in 1973. During this time, the world's rate of inflation has accelerated and the level of employment and rate of growth have fallen, giving rise to an unusually high level of spare capacity in the world economy. Not only have there been signs of inefficiency, however, there have also been signs of increasing inequity. Particularly hard hit by world economic developments have been the poorest or least developed countries which have been unable to attract the necessary capital to maintain growth in the face of the deterioration in their balance of payments. In many cases, these countries which already had per capita income levels of $\$ 250$ and less have actually experienced falling standards of living. It is the basic theme of the Brandt Report that appropriate international action can make a significant contribution towards dealing with the twin problems of inefficiency and inequity.

\section{World Keynesianism}

Although at no point in the Report is there a clear statement of the economic model upon which its proposals are based, careful reading can leave little doubt about the model that was implicitly adopted.' The Commission argues that, in conditions of underutilised capacity, a transfer of resources to developing countries will have the effect of raising world aggregate demand and of lowering the level of world unemployment. According to the Report, developing countries will benefit from such a transfer in terms of the alleviation of the foreign-exchange gap which currently constrains their development, while developed countries will gain from the expansion in demand for their exports. Encapsulated in the preceding policy prescription are a number of assumptions with regard to

\footnotetext{
*First published in The World Today. December 1980. Our thanks are due both to the author and to the original publication for permission to reprint this article.

${ }^{1}$ The model is perhaps most clearly reflected in chapters 3 and 15 of the Report.
}

Bulletin. 1981. vol 12 no 2. Institute of Development Studies. Sussex economic principles. The most fundamental of these relates to the basic macroeconomic relationships which determine the performance of an economy.

Keynesian analysis which, not coincidentally, grew out of the stagnation of the $1930 \mathrm{~s}$, attributes unemployment primarily to a deficiency in aggregate demand. On the basis of such analysis, the cure is simply to encourage demand to expand. Fiscal policy represents the prime vehicle through which this expansion may be achieved, and this may be manipulated in such a way as either to adjust the overall balance between total government expenditure and total tax receipts, or to alter the distribution of a given level of expenditure and taxation. In the latter case, the efficacy with which fiscal policy influences aggregate demand depends on the fact that different groups within society exhibit different propensities to spend and save. If relatively rich people have lower propensities to spend at the margin of income than do relatively poor people, then it follows that a redistribution of income from rich to poor will serve to raise the community's average propensity to spend and this will, in turn, raise the level of aggregate demand. Keynesians maintain that this increase in aggregate demand will not have any significantly adverse effect on the price level or the rate of inflation for the simple reason that it will be matched by an equivalent increase in the real supply of goods and services. It will be output and not prices that in the main will respond to the increase in demand.

The functional use of fiscal policy in this way, which characterises Keynesian economics, also underpins the Brandt Report. The difference between the conventional Keynesian model and the model employed by the Brandt Commission relates to its spatial application. The Brandt Report is Keynesianism at the world level. In certain ways, this spatial aspect is strategic, since many of the criticisms that have been levelled at conventional Keynesian wisdom have, in particular, challenged its applicability to an open economy. Economists subscribing to the New Cambridge school, for instance, maintain that most of the impact of expansionary fiscal policy is in fact felt in terms of a deterioration in the balance of payments rather than an improvement in the level of employment. This criticism, however, constitutes less of a problem as the economy under consideration becomes less open. In the extreme, the problem disappears altogether for a closed economy-ie an economy with no trading 
relationships-since in these circumstances there is no balance of payments as such. The important point here is, of course, that the world economy is a closed economy.

The fact that the world economy is closed is also important for another reason. A central component of Keynesian theory is the concept of the multiplier. This suggests that any initial expansion in an autonomous element of expenditure will bring about a larger or multiplied increase in national income. The size of the multiplier will vary inversely with the size of leakages in the circular flow of income such as saving, direct taxation and imports. For the world economy there will be no import leakage, and therefore, as compared with trading economies, the size of the multiplier will tend to be higher.

For these reasons, it might seem at first sight that Keynesian economics is more appropriate to the world economy than to individual open economies and that the Brandt Commission has, therefore, shown considerable sophistication in choosing to use this model.

\section{Monetarist Criticisms}

Monetarists $^{2}$ will argue that the Brandt Commission misinterprets the causes of the current world economic situation and, as a consequence, goes on to advocate completely inappropriate policies that will do more harm than good. Monetarists maintain either that the currently high levels of unemployment are not the result of a deficiency in world aggregate demand, but of social and structural changes, or, alternatively, that unemployment is a largely inescapable side-effect of reducing the rate of inflation. In explaining the world's poor economic performance during the $1970 \mathrm{~s}$, they reject the view that this has been caused by the rise in the price of oil, seeing this argument as a simplistic and invalid example of post hoc ergo propter hoc. Instead, they maintain that an over-expansion of the world's supply of money was the major cause of both the acceleration in the world's rate of inflation and the increase in unemployment. According to monetarist doctrine, the policies advocated in the Brandt Report will at best have a beneficial effect on real output only in the short run and will, in the long run, unambiguously serve to increase the rate of inflation, with no gain being felt in terms of additional output.

What the Commission regards as the major cause of inflation is, in fact, left somewhat ambiguous in its Report. In some places, the Commission's choice of

${ }^{2}$ The terms 'Keynesian' and 'monetarist' are used as a convenient shorthand. There is still considerable disagreement amongst economists as to what precisely constitutes the Keynesian model and whether. in any case. this model accurately reflects the one that Keynes had in mind. Even more disagreement exists over the precise definition of 'monetarist. Such doctrinal controversy is. however. not directly relevant to this particular article and the interpretation of the terms as used here should be clear from the text. words seems to be based on a fairly conventional curvilinear Phillips curve relationship between aggregate demand and price inflation. In others, it seems to be assumed that the Phillips curve has a pronounced $L$ shape with the angle of the $L$ occurring at full employment, while in still other places it appears that cost inflation is assumed. Thus, on page 241 of the Report, it is argued that, 'the present continuing high unemployment causes uncertainty about future levels of demand and employment and generates cumulative reactions in ways which may result in greater costpush and inflationary tendencies, rather than less.' The argument here seems to be that any moderating effect on prices which is normally attributed to falling demand has been outweighed by the cost inflation which has been caused by uncertainty about future levels of output. Although, at a superficial level, this argument is supported by the fact that during the mid1970 s inflation was accelerating at the same time as unemployment was high and rising, the simultaneous existence of unemployment and inflation may also be explained in quite different terms. Critics of the traditional Phillips curve point to the crucial significance of expectations in the inflationary process. Under an expectations model of inflation, policies designed to bring about an expansion in demand will fail to raise the level of employment above its so-called natural rate $^{3}$ unless there is a period of time during which workers fail to adjust their expectations about the rate of inflation to the actual rate that is being experienced; even then, the higher than natural rate of employment will only exist for the duration of this adjustment lag. As soon as workers bring their expectations into line with actual experience, employment returns to its natural rate. According to the expectations model, and assuming that the economy is currently at its natural rate of employment, any benefit for employment from expansionary demand policy will be purely transitory. In the long run, there will be no trade-off between inflation and employment. Indeed, the consequences for employment may for a significant period of time be negative as governments are forced to try and bring inflation down from the high rates that their own expansionary policies induce. Any shortterm benefit in terms of lower than natural unemployment will be counterbalanced by a subsequent cost in terms of higher than natural unemployment. The expectations model suggests that expansionary demand policies will only have a permanent effect on real output and employment for as long as the level of unemployment is above its natural rate.

\footnotetext{
${ }^{3}$ The natural rate of unemployment is the rate that exists when the labour market is in equilibrium. ie. when the real wage is at a level which equates the demand for labour with the supply of labour. It is unemployment caused by factors other than a deficiency in aggregate demand such as labour immobility and the state of workers preferences as between work and leisure. While being a concept which monetarists have greatly used. it is one about which it is difficult to be precise and to which it is difficult to attach a numerical value
} 
Applying this analysis to the world economy, it follows that if world employment is currently at its natural rate, then the principal effect of the policies advocated by the Brandt Report will be to raise the world rate of inflation. More appropriate than expansionary policies would be policies directed towards lowering the natural rate of unemployment by encouraging the structural changes in the world economy that market forces dictate. On this basis, the interventionist policies associated with the Brandt Report would be seen as impeding this necessary structural change and as imposing continuing economic inefficiency on the world.

\section{Concluding Remarks}

Two apparently very different views about both the causes of the world's economic problems and the policies which might be pursued in order to ameliorate them emerge from the discussion.

The Brandt Commission sees the rise in the price of oil as having had a major deflationary impact on the world economy. It feels that the recycling of oil surpluses through the International Monetary Fund and the Eurocurrency market has made a significant contribution to the maintenance of output and employment levels, and goes on to advocate an extension of this type of policy approach through various specific mechanisms. The intended effect of these policies is to reduce the level of world unemployment and to raise the level of real output. The prime movers in this approach, which is based on expanding world aggregate demand, are the developing countries to which recycling will transfer the necessary financial resources.

In contrast, monetarist critics of the Brandt Report argue that it has been over-expansion in the past that has caused most of the world's economic problems. They argue that high unemployment and low output reflect both this and the rapid structural changes that have been occurring in the world economy. Policy based on a misinterpretation of the causes of the problem will lead to higher rates of inflation and, if anything, higher rather than lower unemployment. They support a non-interventionist approach which relies on market forces.

Which view is correct? On the basis of currently available evidence, it is difficult, if not impossible, to say in advance of the policies being tried. The central issue at stake relates to the nature of world unemployment. If this is, at least in part, the result of a deficiency in aggregate world demand, then it is likely that policies of the kind contained in the Brandt Report will have some beneficial effect. If, on the other hand, unemployment is of a non-demand deficient type, then expansionary policies will be harmful rather than beneficial.

The problem is that nobody can be sure about what constitutes the current natural rate of unemployment for the world economy. As a consequence, the effects of policies become uncertain and unpredictable. This is even more true in an economic environment that is characterised by considerable instability. Even where it seems as though a stable macroeconomic relationship has been discovered upon which policy may be based, there is no guarantee that a relationship that has held in the past will continue to hold in the future. There is simply not enough information from which to choose between competing theories and on the basis of which to select policy.

In such a situation, it is perhaps not surprising that economists are in some measure of disagreement over macroeconomic theory and policy. It then becomes important to draw attention to the fact that alternative theories do exist and that they lead to different policy conclusions. The advocacy of one particular policy, therefore, becomes as much an article of faith as the result of scientific selection. The Brandt Report should be seen in this light.

Are its policies likely to be accepted and implemented? As mentioned in the introduction, their reception amongst those that matter has up to now been less than enthusiastic. This is precisely the reception that might have been predicted. A number of governments in the world are showing disillusionment with Keynesian economics and, on this basis, would be expected to reject the Brandt Report. Others that are utterly confused by current macroeconomics are legitimately uncertain about the effects that the policies advocated in the Report would have. It is probably an accurate observation that in conditions of uncertainty there is a preference to do nothing. By default, if for no other reason, it seems probable therefore that critics of the Report will win the policy battle, and the Brandt Report will enter the history books as just another well-intentioned Report that in practical terms led to nothing. 